\title{
Impact of maternal postnatal depression on cognitive development of young children
}

\author{
S R COGILL, H L CAPLAN, HEATHER ALEXANDRA, KAY MORDECAI ROBSON, \\ R KUMAR
}

\begin{abstract}
Ninety four women and their first born children took part in a longitudinal study of maternal mental health during pregnancy and after delivery. The children's cognitive functioning was assessed at age 4 using the McCarthy scales, without knowledge of the mothers' psychiatric history or current health. As expected girls performed slightly better than boys and children from middle class and professional families did better than children from working class homes, as did children whose mothers had achieved at least one $A$ level at school. Significant intellectual deficits were found in the children whose mothers had suffered with depression, but only when this depression occurred in the first year of the child's life. Marital conflict and a history of paternal psychiatric problems were independently linked with lower cognitive test scores; together with a working class home background these were the only factors that contributed to the deleterious effect of maternal postnatal depression.
\end{abstract}

\section{Introduction}

An infant's early relationship with its parents, particularly the mother, lays the foundation for later personality and intellectual development. Parental psychiatric disturbances can therefore play a major part in the genesis of behavioural disorders in children, although in most cases the main risk stems not from the illness itself but from associated family disturbance. ${ }^{1-3}$ The high prevalence of clinically important emotional disturbance in mothers of preschool children is now widely recognised, ${ }^{45}$ and maternal depression has been associated with concurrent behaviour problems in 2 and 3 year olds. $^{6}$ Additional links have been made with marital discord,

\footnotetext{
Department of Child and Adolescent Psychiatry, University College Hospital London WC1

S R COGILL, BA, MPHIL, principal clinical psychologist

H L CAPLAN, FRACP, FRCPSYCH, consultant child psychiatrist

HEATHER ALEXANDRA, BA, MSC, research psychologist

Institute of Psychiatry, London SE5 8AF

KAY MORDECAI ROBSON, PHD, lecturer

R KUMAR, MD, FRCPSYCH, reader in psychosomatic medicine

Correspondence to: Dr Kumar.
}

parental personality disorder and social disadvantage, the presence of other young children in the home, and the sex of the index child. ${ }^{\times 110}$

Childbirth is one of the times when women are most prone to develop psychiatric disturbance, " but little is known of possible long term sequelae in the children of mothers who experience postpartum psychotic or neurotic depression. For example, Weissman et al commented that severely depressed mothers with newborn infants were virtually immobilised in their maternal role, ${ }^{12}$ and Rutter observed that among the important influences on a child's early cognitive development are the provision by parents of a variety of activities and opportunities for play and conversation, responsiveness to the child's signals, and the teaching of specific skills. ${ }^{3}$ Such influences may be adversely affected by postnatal depression through impaired mother-infant interaction ${ }^{13}$ and attachment, ${ }^{14}$ is but reports suggest that the cognitive sequelae in children of parents with a psychiatric disorder either are small or have not been established. ${ }^{3}$

Most studies have been retrospective, and the appropriate strategy for research into child development is by longitudinal, controlled inquiry. ${ }^{16}{ }^{17}$ We are aware of three such studies of the potential longer term impact of postnatal illness, but they provide only equivocal evidence that maternal postnatal depression per se significantly contributes to the subsequent development of behavioural disturbances in 3 and 4 year old children. ${ }^{18-20}$ We carried out a longitudinal study of the mental health and social circumstances of 119 first time mothers, beginning in early pregnancy and continuing up to four years post partum. ${ }^{15}$ Around the time of their fourth birthdays the offspring of 99 women who remained in the survey were investigated by members of the research team, who had no knowledge of the mothers' histories. Tests of the children's cognitive development are reported here, and measures of temperament and behavioural disturbance will be described later. ${ }^{21-23}$

\footnotetext{
Methods

The children-When they were 4 years old the children were seen at home by a psychologist, who administered the McCarthy scales of children's abilities. ${ }^{21}$ These comprise standardised tests of verbal, perceptual, quantitative, memory, and motor skills, and the first three subscales are combined to give a general cognitive index, which is a reliable measure of cognitive development at this age. One of the children was away and in four instances the tests could not be completed satisfactorily. Further home visits could not
} 
TABLE I-Relation between maternal depression and children's performance at age 4 on McCarthy scales of children's abilities

\begin{tabular}{|c|c|c|c|}
\hline Maternal psychiatric disturbance & $\begin{array}{c}\text { No of } \\
\text { women }\end{array}$ & $\begin{array}{l}\text { Children's general } \\
\text { cognitive index } \\
\text { (mean }(\mathrm{SE}))\end{array}$ & $\begin{array}{l}\text { Significance of } \\
\text { difference } \\
(\mathrm{df}=92)\end{array}$ \\
\hline \multicolumn{4}{|l|}{ Psychiatric history: } \\
\hline $\begin{array}{l}\text { Yes } \\
\text { No }\end{array}$ & $\begin{array}{l}31 \\
63\end{array}$ & $\begin{array}{l}111 \cdot 3(2 \cdot 2) \\
110 \cdot 7(2 \cdot 5)\end{array}$ & \multirow{2}{*}{$t=0 \cdot 13$} \\
\hline Depression in pregnancy: & & & \\
\hline $\begin{array}{l}\text { Present: } \\
\text { Absent }\end{array}$ & $\begin{array}{l}19 \\
75\end{array}$ & $\left.\begin{array}{l}111 \cdot 5(2 \cdot 8) \\
110 \cdot 8(2 \cdot 1)\end{array}\right\}$ & $t=0 \cdot 16$ \\
\hline \multicolumn{4}{|l|}{ Postnatal depression: } \\
\hline $\begin{array}{l}\text { 0-3 months: } \\
\text { Present } \\
\text { Absent }\end{array}$ & $\begin{array}{l}15 \\
79\end{array}$ & $\left.\begin{array}{l}101 \cdot 1(7 \cdot 0) \\
112 \cdot 8(1 \cdot 6)\end{array}\right\}$ & $t=2.46, \mathrm{p}<0.02$ \\
\hline $\begin{array}{l}\text { 0-12 months: } \\
\text { Present } \\
\text { Absent }\end{array}$ & $\begin{array}{l}22^{\star} \\
72\end{array}$ & $\left.\begin{array}{l}101 \cdot 3(4 \cdot 8) \\
113 \cdot 8(1 \cdot 7)\end{array}\right\}$ & $t=3 \cdot 10, \mathrm{p}<0.005$ \\
\hline $\begin{array}{l}\text { Concurrent depression (at } 4 \text { years): } \\
\text { Present } \\
\text { Absent }\end{array}$ & $\begin{array}{r}8 \\
86\end{array}$ & $\left.\begin{array}{l}111 \cdot 0(4 \cdot 6) \\
110 \cdot 9(1 \cdot 9)\end{array}\right\}$ & $t=0.01$ \\
\hline
\end{tabular}

*The 15 women who were rated as clinically depressed in the three months after delivery are included here. and 12 months postnatally, and four years after the birth; they were compared in each instance with the scores of the remaining children Psychiatric history was defined as a course of treatment from the family doctor or a specialist for nervous or emotional problems before pregnancy The children's performance on the McCarthy scales was significantly reduced by about 10 points in association with maternal depression only in the first year of their lives. All the women who were depressed in the perio up to three months post partum were included among the group of $2 \mathrm{~F}$. women rated as depressed at some time up to 12 months after delivery Comparisons by $t$ testing of the McCarthy subscale scores for the corres $\$$ ponding 22 children versus the rest also showed significant or neaft significant decrements (verbal $4 \cdot 2$ points, $p<0 \cdot 1$; perceptual $7 \cdot 7$ points 0 $\mathrm{p}<0.001$; quantitative 4.3 points, $\mathrm{p}<0.1$; memory 4.6 points, $\mathrm{p}<0.05$; motor performance $7 \cdot 0$ points, $\mathrm{p}<0.005$ )

Many factors influence the cognitive development of children or theif level of performance, and table II summarises the results that were obtaineof with the 94 children, who were subdivided into groups according to

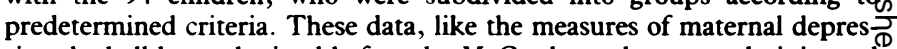
sion, had all been obtained before the McCarthy scales were administered and were therefore free from bias. Information on the father's educationafs attainment was lacking, and although the criterion for defining the father's-

TABLE II-Correlation of children's cognitive ability and development with their gender and social background

\begin{tabular}{|c|c|c|c|c|}
\hline & No & $\begin{array}{l}\text { Children's general } \\
\text { cognitive index } \\
(\text { mean }(\mathrm{SE}))\end{array}$ & $\begin{array}{l}t \text { Tests for } \\
\text { significances of } \\
\text { differences } \\
\text { (two tailed) }\end{array}$ & $\begin{array}{c}\text { Tests for interactions } \\
\text { with postnatal } \\
\text { depression } \\
(0.12 \text { months) } \\
\text { (two way analyses of } \\
\text { variance) }\end{array}$ \\
\hline \multicolumn{5}{|l|}{ Sex: } \\
\hline $\begin{array}{l}\text { Girl } \\
\text { Boy }\end{array}$ & 52 & $114 \cdot 8(1 \cdot 8)\}$ & \multirow{2}{*}{$t=2.50, \mathrm{p}<0.02$} & $\mathrm{~F}<1$ \\
\hline \multicolumn{4}{|c|}{ Social class: } & \\
\hline $\begin{array}{l}1-3 N \\
3 M-5\end{array}$ & $\begin{array}{l}74 \\
20\end{array}$ & $\left.\begin{array}{l}112 \cdot 7(2 \cdot 0) \\
104 \cdot 5(3 \cdot 9)\end{array}\right\}$ & $t=1.91, \mathrm{p}=0.06$ & $F=3 \cdot 85, p=0.052$ \\
\hline \multicolumn{5}{|c|}{ Maternal education: } \\
\hline $\begin{array}{l}\text { O levels } \\
\text { A levels }\end{array}$ & $\begin{array}{l}43 \\
51\end{array}$ & $\left.\begin{array}{l}107 \cdot 0(2 \cdot 4) \\
114 \cdot 2(2 \cdot 5)\end{array}\right\}$ & $t=2.06, \mathrm{p}<0.05$ & $\mathrm{~F}<1$ \\
\hline \multicolumn{5}{|c|}{ Prechtl index: } \\
\hline $\begin{array}{l}0-6 \\
7+\end{array}$ & $\begin{array}{l}70 \\
23\end{array}$ & $\left.\begin{array}{l}111 \cdot 2(2 \cdot 3) \\
110 \cdot 1(2 \cdot 6)\end{array}\right\}$ & \multirow[t]{2}{*}{$t=0 \cdot 25$} & $\mathrm{~F}<1$ \\
\hline \multicolumn{4}{|c|}{ Marital conflict: } & \\
\hline $\begin{array}{l}\text { Present } \\
\text { Absent }\end{array}$ & $\begin{array}{l}13 \\
81\end{array}$ & $\left.\begin{array}{l}100 \cdot 3(7 \cdot 6) \\
112 \cdot 6(1 \cdot 6)\end{array}\right\}$ & $t=2 \cdot 44, \mathrm{p}<0.02$ & $F=4.68, p<0.05$ \\
\hline \multicolumn{5}{|c|}{ Husband's psychiatric history: } \\
\hline $\begin{array}{l}\text { Present } \\
\text { Absent }\end{array}$ & $\begin{array}{l}10 \\
84\end{array}$ & $\left.\begin{array}{r}95.9(9.4) \\
112.7(1.6)\end{array}\right\}$ & $t=3.02, \mathrm{p}<0.005$ & $\mathrm{~F}=6.95, \mathrm{p}<0.01$ \\
\hline
\end{tabular}

Marital conflict was rated during pregnancy-that is, before the onset of postnatal depression-and the interaction was also significant when analysed against depression occurring during the first three months of the child's life $(\mathrm{p}<0 \cdot 02)$; the same applied to the husband's psychiatric history $(\mathrm{p}<0.005)$. The interaction between parental sacial class and in the first three months bordered on significan $(F=3 \cdot 20, d f=1,90, p<0 \cdot 1)$. A wrerking class back and maternal depression two other variables in that it was not a precursor of postnatal depression. ${ }^{15}$

be arranged in the time available, and complete measures were therefore obtained for 94 children.

The mothers-The methodology has been described elsewhere ${ }^{15}$; the sample was a consecutive series of first time mothers attending the obstetric clinic of a London teaching hospital. Only mothers who spoke adequate English, lived with a husband or partner, and booked obstetric care by the 14th week of pregnancy were included. The mothers were clinically assessed at intervals by a psychiatrist using a standardised semistructured interview, ${ }^{2+}$ and the children of women who were diagnosed as having depression at various stages - that is, during pregnancy, up to three months post partum, up to 12 months post partum, and when the children were 4 years old-were compared with the rest of the sample. Information was also available from the original survey about the mother's personal and family psychiatric history, social class, and educational achievement. The quality of the marital relationship was assessed during pregnancy and when the child was 4 years old. Obstetric and paediatric case notes were scrutinised and a score compiled reflecting the degree of risk to the child's health according to the method of Prechtl ${ }^{2 \varsigma}$ : one set of case notes was lost, and so for this measure there were 93 subjects.

Analysis of results-Hypotheses were formulated about factors that might have adverse effects on children's psychological development, ${ }^{15}$ and these were examined by means of $t$ tests and two way analyses of variance.

\section{Results}

Table I shows the average scores on the general cognitive index of children whose mothers had been clinically depressed during pregnancy, up to three psychiatric history was the same as for the mother, she alone was questioned Table II shows a series of significant differences in children's generaß cognitive index in relation to several parental variables, the differences being in the expected direction in all cases. Infants exposed to greater perinatal hazard (raised Prechtl scores) did not, however, score significantly
lower on the McCarthy scales.

Two way analyses of variance provide a way of testing for interactions between main effects-for example, children of mothers with postnatal depression may develop more slowly because they also come from socio economically disadvantaged homes. Table II suggests that this was indeef the case. Two other significant interactions emerged, and both concerned the spouse of the depressed woman-namely, marital conflict and reported past psychiatric problems in the husband. Both these factors, but not sociab class, have previously been shown to predict postnatal depression. ${ }^{15}$

Other incidental comparisons showed that depression during pregnancy was not associated with any increase in perinatal hazard (Prechtl indexs scores), and when there was some evidence of neonatal health problems (Prechtl scores of 7 and above) this did not link with later postnatab depression. Women who reported conflict in the marriage during pregnancs, were more likely to report similar conflict when the child was $4\left(\chi^{2}=6 \cdot 15 \stackrel{0}{\circ}\right.$ $\mathrm{df}=1, \mathrm{p}<0.05)$, and it is therefore difficult to disentangle the interactive influence of marital conflict with maternal depression on the developingo child. The lack of a link between concurrent maternal depression and the child's cognitive level at age 4 suggests that the impact of maternap depression on cognitive development is long term rather than transitory although the numbers were small and the mothers were not assessect clinically in the intervening three years. 


\section{Discussion}

The findings of lower overall cognitive performance in boys, in children from working class families, and in children of mothers who themselves had been relatively poor achievers educationally are not new and bear out the reliability of the McCarthy tests in 4 year olds. ${ }^{26}$ What is new is the selective correlation between maternal depression early in the child's life and subsequent poorer cognitive performance. The longitudinal design of the study ensured that the measures in the children were independent of the assessments of the mothers, and the cognitive tests were not subject to bias, such as may occur when mothers report behavioural problems in their children.

Causal links cannot automatically be inferred from correlations, but the independence of the association between maternal postnatal depression and children's lower cognitive performance from the sex of the child and the mother's educational achievement, and its interdependence with marital problems, father's psychiatric history, and parental social class, point to ways in which maternal postnata depression might exert its impact. The sample we studied comprised first born children, who may be particularly sensitive to impaired relationships with and between their parents.

About one in every 10 women becomes clinically depressed in the months after childbirth, ${ }^{11}{ }^{15}{ }_{28}$ and the size of the problem alone therefore merits attention. Our findings of possible deleterious effects of postnatal depression on the cognitive development of young children require replication and more extensive follow up.

This research was supported by a grant from the Mental Health Foundation. We are grateful to the families who participated in the survey and to Ms Valerie Scott, Mr P Conlon, and Mr C Sharp for help with analysis of the data.

\section{References}

Rutter M, Quinton D. Parental psychiatric disorder: effect on children. Psychol Med 1984;14: 853-80

Billing AG, Moos RH. Comparisons of children of depressed and non-depressed parents: a socialenvironmental perspective. f A hnorm Child Psychol 1983:11:463-86.
3 Rutter M. Family and school influences on cognitive development. I Child Psychol Psychiatr. $1985 ; 26: 683-704$

4 Brown G, Harris T. Social ongins of depression. London: Tavistock, 1978

5 Moss P, Plewis I. Mental distress in mothers of pre-school children in inner London. Psychol Med $1977 ; 7: 641-52$

6. Richman N, Stevenson JE, Graham PJ. Prevalence of behavioural problems in three year old children: an epidemiological study in a London borough. $f$ Child Psychol Psychiatry children: an

7 Mills M, Puckering C, Pound A, Cox AD. What is it about depressed mothers that influences their children's functioning? In: Stevenson J, ed. Recent research in developmental psychopatholog Oxford: Pergamon (in press). (Joumal of Child Psychology and Psychiatry monograph, supplement 4.

8 Rutter $M$, Cox A, Tupling C, Berger M, Yule WL. Attainment and adjustment in two geographical areas. I. The prevalence of psychiatric disorder. Brf Psychiatry 1975;126:493-509.

Rutter M, Yule B, Quinton D, Rowlands D, Yule W, Berger M. Attainment and adjustment in two geographical areas. II. Some factors accounting for area differences. Br $\mathcal{J}$ Psychiatny 1975;126:520-33

10 Cooper SF, Leach C, Stover D, Tonge WL. The children of psychiatric patients: clinical findings. Br J Psychiatn 1977;131:514-22.

11 Brockington IF, Kumar R. Motherhood and mental illness. London: Academic Press, 1982.

12 Weissman MM, Paykel ES, Klerman GL. The depressed woman as a mother. Soc Psychiat 1972;7:98-108

13 Livingood $A B$, Daen $P$, Smith $B$. The depressed mother as a source of stimulation for her infant J Clin Psychol 1983;39:369-75.

14 Herbert M. Sluckin W. Sluckin A. Mother-to-infant "bonding." 7 Child Psychol Psychiatn. 1982:23:205-21

15 Kumar R, Robson KM. A prospective study of emotional disorders in childbearing women. $\mathrm{Br} f$ Psychialn 1984:144:35.47.

16 Chess S. Thomas A, Birch HG, Hertzig M. Implications of a longitudinal study of child development for child psychiatry. Am $\mathcal{F}$ Psychiatry 1960;117:434-41.

17 Rutter $M$, Birch HG, Thomas A, Chess S. Temperamental characteristics in infancy and the later development of behavioural disorders. Br $\mathcal{F}$ Psychiatry 1964;110:651-61

18 Uddenberg N, Englesson I. Prognosis of post partum mental disturbance. Acta Psychiatr Scand 1978:58:201-12

19 Ghodsian M, Zaiicek E, Wolkind S. A longitudinal study of maternal depression and child behaviour problems. F Child Psychol Psychiatn 1984:25:91-109.

20 W'rate RM, Roonev AC, Thomas PF, Cox JL. Postnatal depression and child development: a three year follow up study. Br F Psychiatry 1985:146:622-7.

21 McCarthy D. Manual for the McCarths scales of children's abilutes. New York: Psychological Corporation, 1972

2 Carev $W_{B}$, MCDevitt SC. Revision of the infant temperament questionnaire Pediutrics $1978: 61: 735-9$

23 Richman N, Graham PJ. A behavioural screening questionnaire for use with three year old children: preliminary findings. I Child Psychol Psychiatry 1971:12:5-33.

24 Goldberg D, Eastwood MR, Kedward HB, Shepherd M. A standardised psychiatric interview for Goldberg D. Eastwond MR, Kedward HB, Shepherd M. A standar
use in community surveys. Br f Prev Soc Med 1970;24:18-23.

25 Prechtl HFR. Neurological sequelac of prenatal and perinatal complications, Br Med 7 $1967 ;$ ii: $763-7$

26 Davie R, Butler R, Goldstein H. From birth to seven: a report on the National Child Development itudy: London: Longman, 1972

27 Madge N, lizard J. Intelligence. In: Rutter M, ed. Scientific foundations of developmental psychiatry. London: Heinemann, 1980:245-65.

28 Pitt B. Atypical depression following childbirth. Br f Psychiatry 1968;114:1325-35.

\title{
Treatment of first episodes of acute anal fissure: prospective randomised study of lignocaine ointment versus hydrocortisone ointment or warm sitz baths plus bran
}

\author{
STEEN LINDKÆR JENSEN
}

\begin{abstract}
One hundred and three patients with an acute first episode of posterior anal fissure were randomised to receive a three week trial of lignocaine ointment $(n=33)$ versus hydrocortisone ointment $(n=35)$ or warm sitz baths combined with an intake of unprocessed bran $(n=35)$. Seven patients were withdrawn owing to failure to adhere to the trial protocol. After one and two weeks of treatment symptomatic relief was significantly better among
\end{abstract}

General Practice and Surgical Clinic, Lægehuset, Rønnebær Allé, Elsinore, and Department of Surgical Gastroenterology C, Rigshospitalet, University of Copenhagen, Denmark

STEEN LINDKÆR JENSEN, MD, DRMED, senior registrar

Correspondence to: Dr Steen Lindkær Jensen, Department of Surgical Gastroenterology C2122, Rigshospitalet, Blegdamsvej 9, DK-2100 Copenhagen 0, Denmark. patients treated with sitz baths and bran than among patients treated with lignocaine ointment or hydrocortisone ointment. After three weeks there was no difference in symptomatic relief among the three groups. Patients treated with lignocaine, however, had significantly fewer healed fissures $(60 \%)$ than patients treated with hydrocortisone $(82 \cdot 4 \%)$ or warm sitz baths and bran $(87 \%)$.

In this study warm sitz baths plus an intake of unprocessed bran came out as the treatment of choice for an acute first episode of posterior anal fissure. This treatment is cheap, has no potential serious side effects, and brings the best and quickest relief of symptoms.

\section{Introduction}

Treatment of an acute anal fissure aims at relieving pain and reflex spasm often caused by a hard stool. Decisions on treatment seem to be based on clinical experience rather than on clinical or scientific 